\title{
Percepção docente sobre inveja, bem-estar subjetivo e saúde mental: um estudo exploratório em instituições de ensino superior públicas
}

Este estudo tem como objetivo identificar a percepção de docentes de instituições ensino públicas sobre inveja, bem-estar subjetivo e saúde mental, por meio da técnica de associação livre de palavras (TALP). Trata-se de uma pesquisa qualitativa realizada com uma amostra de 176 docentes. Os dados foram coletados por meio de uma survey online. As respostas foram processadas no software IRAMUTEQ versão 7 e analisadas a partir da técnica de classificação hierárquica descendente, similitude e nuvem de palavras. Foram observadas 1564 ocorrências de palavras, sendo 479 formas distintas. Destas, foram encontradas 282 ( $58,87 \%$ ) palavras equiparadas por meio hierárquico descendente que resultaram em 6 categorias: Inveja Tóxica, Inveja dolorosa, Cuidado mental, Equilíbrio, Aspectos desejável e Qualidade de Vida. Por fim, conclui-se uma melhor compreensão dos termos que envolvem tais construtos na perspectiva de professores universitários de instituições públicas em seu local de trabalho, fornecer subsídios para mobilizar práticas voltadas a melhorar as relações sociais nesse ambiente.

Palavras-chave: Inveja; Bem-estar subjetivo; Saúde mental; Percepção; Docentes; Ensino Público.

\section{Teacher's perception on envy, subjective well-being and mental health: an exploratory study in public higher education institutions}

This study aims to identify the perception of teachers of public education institutions about envy, subjective well-being and mental health, through the technique of free word association (TALP). It is a qualitative research carried out with a sample of 176 teachers. The data were collected through an online survey. The answers were processed in the software IRAMUTEQ version 7 and analyzed using the descending hierarchical classification technique, similarity and word cloud. There were 1564 occurrences of words, 479 different forms. Of these, 282 (58.87\%) words were found using descending hierarchical means that resulted in 6 categories: Toxic Envy, Painful Envy, Mental Care, Balance, Desirable Aspects and Quality of Life. Finally, it concludes a better understanding of the terms that involve such constructs from the perspective of university professors from public institutions in their workplace, providing subsidies to mobilize practices aimed at improving social relations in this environment.

Keywords: Envy; Subjective well-being; Mental health; Perception; Teachers; Public education.

Topic: Recursos Humanos

Reviewed anonymously in the process of blind peer
Received: 09/03/2020

Approved: 02/04/2020
Mary Dayane Souza Silva (iD

Universidade Federal do Pernambuco, Brasil

http://lattes.cnpq.br/9393194690113819

http://orcid.org/0000-0003-3144-7588

m.dayane.silva@gmail.com

\section{Antonio Roazzi (iD)}

Universidade Federal do Pernambuco, Brasil

http://lattes.cnpq.br/6108730498633062

http://orcid.org/0000-0001-6411-2763

roazzi@gmail.com

Francisca Rozângela Lopes de Sousa (iD)

Universidade Estadual da Paraíba, Brasil

http://lattes.cnpq.br/7564029475757969

http://orcid.org/0000-0003-2770-7666

rhozeadm@hotmail.com

\section{Geymeesson Brito da Silva (iD \\ Universidade Federal do Pernambuco, Brasil \\ http://lattes.cnpq.br/73331740582805322 \\ http://orcid.org/0000-0001-5645-7067 \\ geimerson18@hotmail.com \\ Cinthia Moura Frade (iD) \\ Universidade Estadual da Paraíba, Brasil \\ http://lattes.cnpq.br/5264348035661218 \\ http://orcid.org/0000-0002-2826-816X \\ admcinthiafrade@gmail.com}

Referencing this:

SILVA, M. D. S.; RPAZZI, A.; SOUSA, F. R. L.; SILVA, G. B.; FRADE, C. M. Percepção docente sobre inveja, bem-estar subjetivo e saúde mental um estudo exploratório em instituições de ensino superior públicas. Revista Brasileira de Administração Científica, v.11, n.2, p.66-80, 2020. DOI: http://doi.org/10.6008/CBPC2179-684X.2020.002.0005 


\section{INTRODUÇÃO}

A inveja pode emergir de diferentes variáveis relacionadas a conquista, posse, desejo sobre uma qualidade ou vantagem tida como superior pelo indivíduo que possui inveja, provocando uma cobiça por obter o que outros possuem (HENNIGER et al., 2015). Podendo-se referir também a um anseio de que o outro perca qualquer vantagem que lhe pareça dar alguma vantagem a seu objeto de inveja (PARROTT et al., 1993). Portanto, a inveja pode ser baseada em uma ascensão ou comparação social provocada pela motivação para nivelar essa diferença entre o eu e o ego superior (VEN et al., 2009).

Assim, algumas vantagens são invejadas não necessariamente porque os invejosos considerem que estas sejam importantes, mas porque essas vantagens têm alto nível social. Isso implica que a inveja resulta de uma ameaça à status social. Mais precisamente, a inveja é baseada em uma percepção de perigo, relacionada a perder de respeito e de influência social sobre os olhos dos outros (CRUSIUS et al., 2017; FISKE, 2010).

Cada indivíduo tem um julgamento consciente e cognitivo quanto aos seus próprios critérios de satisfação existencial em relação a sua satisfação com a vida, a partir de um conjunto próprio de critérios que refletem a forma como julgam e avaliam a qualidade de suas vidas (PAVOT et al., 2009; SHIN et al., 1978). A satisfação com a vida refere-se ao significado que os sujeitos atribuem à felicidade, a qual difere entre os diferentes os grupos culturais, pois são moldadas por comportamentos individuais, grupais e organizacionais (WOYCIEKOSKI et al., 2012).

O bem-estar subjetivo (BES) envolve uma ampla categoria de respostas cognitivas e emocionais sobre a satisfação com a vida do indivíduo (ALBUQUERQUE et al., 2006). Pois expressa um juízo avaliativo em termos globais ou específicos da vida (GALINHA et al., 2005). Portanto, pode ser compreendido como a satisfação que os indivíduos atribuem a distintas áreas de sua vida, configurando-se assim como um construto multidimensional. Enfatiza uma relação de longo tempo e não apenas um momento, pois frequentemente o que pode vir a fornecer felicidade em um dado momento pode não ser suficiente para produzir o bem-estar subjetivo duradouro.

Assim, a avaliação global de uma pessoa sobre sua satisfação com a vida pode atuar como um importante preditor no julgamento geral deste indivíduo sobre sua saúde, considerando que ambos estão intimamente ligados, uma vez que em alguns casos a saúde pode ter um efeito causal no bem-estar, pois a incidência de satisfação em uma área da vida tende a se estender a outros aspectos do bem-estar subjetivo e, sobre certas circunstâncias o aumento da satisfação com a vida pode melhorar a saúde (STRAUME et al., 2014).

A saúde mental evidenciada pelos indivíduos pode ser usada como um indicador de comportamentos futuros, como o suicídio e, de satisfação com a vida que esteja relacionada a fatores psicológicos (depressão, estresse e ansiedade) que afetam diretamente a saúde e o absenteísmo do trabalhador (BUCZAK-STEC et al., 2018). O efeito sobre a saúde mental pode ser tanto positivo, proporcionando contato social, senso de esforço coletivo e identidade social, quanto negativo como fonte de estresse psicológico relacionado às 
demandas de trabalho e falta de apoio social no local de trabalho (CERCARELLI et al., 2012).

Frente a isso, formulou-se o seguinte questionamento qual a percepção de docentes de instituições ensino públicas sobre inveja, bem-estar subjetivo e saúde mental em seus locais de trabalho? Os problemas da inveja nos docentes podem ser devido a fatores internos ou externos ao trabalho e, sem um gerenciamento eficaz, podem afetar seriamente a produtividade, as perspectivas de carreira e a saúde mental destes. Tendo em vista que, baixos níveis de bem-estar dos funcionários afetam negativamente a produtividade que por sua vez gera um impacto negativo significativo na saúde geral destes (DELOITTE, 2017).

Assim, a construção deste estudo tem como objetivo identificar a percepção de docentes de instituições ensino públicas sobre inveja, bem-estar subjetivo e saúde mental em seu local de trabalho. Os indivíduos afetados por problemas de saúde mental e insatisfação com suas atividades correm um risco substancialmente maior de se tornarem desligados da força de trabalho, sendo menos produtivos (LIM et al., 2000), experimentando níveis mais altos de problemas de saúde física e de se envolverem em acidentes (HARNOIS et al., 2002).

Este estudo está estruturado em cinco seções. Na primeira, apresenta-se uma breve contextualização acerca dos construtos pesquisados. Na seção seguinte, demostra-se os conceitos e as discussões sobre inveja, bem-estar subjetivo e saúde mental. Na terceira e quarta seção se apresentam o procedimento metodológico e a discussão dos resultados respectivamente.

\section{REVISÃO TEÓRICA}

\section{Conceitos de Inveja e sua concepção}

Definir a inveja é uma tarefa aparentemente difícil e complexa. Em primeiro, porque os indivíduos nem sempre são cientes de que suas ações podem ser resultantes de comportamentos invejosos. Em segundo, por envolver uma diversidade de associações, o que gera dificuldade em compreender plenamente sua terminologia descritiva (VIDAILLET, 2008). A inveja tem sido categorizada como "crise espiritual", "pecado", "vicio, "emoção", "processos mentais" (VIDAILLET, 2008). Tendo sido usada para se referir a uma força capaz de destruir e atacar as qualidades que admira em outros ou até mesmo a si próprio (BARROWS, 2002).

A inveja é difícil de categorizar em parte porque, suas reações não são claramente explicitas ou acompanhadas por reações específicas comuns à maioria dos indivíduos. Além disso, o invejar são parcialmente inconscientes para os próprios indivíduos invejosos. Nesses casos, o comportamento pode ser condicionado pela inveja sem que percebam, assim como os sentimentos ligados a ele, como a hostilidade para com a pessoa invejada (VIDAILLET, 2008). Por ser uma emoção maliciosa e destrutiva, muitas vezes resultando em um comportamento prejudicial (SMITH et al., 2007).

Esse 'olhar maliciosamente' que uma pessoa possui e o invejoso não têm. Em seu sentido mais amplo representa um bem, conquista, qualidade, recurso ou até mesmo a simples visão da felicidade e de uma boa 
saúde pode estar na origem da inveja (VIDAILLET, 2008). Conviver com a inveja e suas ações destrutivas embora, sem um alvo específico, objeto de desejo ou vítima essa emoção não tem como surgir e prosperar em um contexto social, também faça parte da condição humana. Sendo criadas, desencadeado por emoções ou reações comportamentais ou em parte por sentimentos resultantes das próprias experiências observadas a partir do outro.

O conceito de inveja em essência é muitas vezes descrito como uma emoção imoral composta de inferioridade, ressentimento para o outro, tendências hostis, culpa (SMITH et al., 2007). Embora, as pessoas não estão dispostas a reconhecê-la ou não estão cientes do fato de que já sentiram ou sente inveja em alguma situação no contexto de trabalho. Por estas razões, a inveja é raramente mencionada nos livros de gestão, embora tenha um forte, por vezes expressiva, influência sobre equipes, relações de trabalho, e sistemas organizacionais negativamente (HARNOIS et al., 2002). Paradoxalmente, também pode, em alguns casos, ser uma fonte de mudança e melhoria.

Portanto, discorrer sobre isso envolve falar sobre lado reprimido, desprezado e mantido em silêncio pelos indivíduos, pois o fracasso, inferioridade, dificuldades em alcançar o que se deseja não são bem vistos por serem associados a aspectos menos gloriosos do eu profissional. Não é o foco aqui discutir a inveja patológica, mas a inveja comum, o tipo de inveja que é provável que afete a maioria dos indivíduos no seu ambiente social, e que ocorre quando menos se espera ao ouvir que um colega foi reconhecido ou que o outro foi felicitado por uma nova conquista profissional, comportamento que leva pôr a acabar invejando quem fez melhor (VIDAILLET, 2008).

Assim, no ambiente de trabalho a inveja pode ser tida como uma emoção comum, envolvida por demandas relacionads a alta produtividade, competição por recursos limitados, oportunidades de promoções, comparações de desempenho, entre outros (STERLING et al., 2016).

\section{Componentes do Bem-Estar Subjetivo e da Saúde Mental}

O campo de estudo do bem-estar, refere-se à análise cientifica da felicidade a partir da percepção dos sujeitos sobre suas próprias vidas (ALBUQUERQUE et al., 2004; WOYCIEKOSKI et al., 2012). A palavra "felicidade" é utilizada para denotar várias situações satisfatórias da vida. No sentido mais amplo, é um conceito que denota tudo que é bom, o que permite associá-lo a termos como bem-estar ou qualidade de vida tanto individual quanto social (VEENHOVEN, 2012). Embora, a satisfação com a vida esteja intrinsicamente relacionada a esta, ainda existem diferentes significados associados à felicidade, como aspectos da vida versus a vida como um todo, bem como o prazer passageiro versus a satisfação duradora.

Nesta perspectiva, têm-se duas vertentes teóricas que discorrem sobre o bem-estar, cuja principal diferença entre ambas reside na sua concepção de felicidade. A primeira é a psicológica em que a ênfase predominante é a visão eudaimónica de felicidade, voltada a sentimentos de propósito, autor realização, crescimento pessoal, busca de serventia ou significado na vida (ALBUQUERQUE et al., 2004; PAVOT et al., 2008).

O bem-estar eudaimónico reflete elementos de uma vida boa que vai além da afeição agradável e da 
satisfação com a vida (TIBERIUS et al., 2010). A segunda vertente é a subjetiva em que predomina a visão hedónica da felicidade (busca pelo prazer e fuga da dor). Essa abordagem reflete uma ênfase em "sentir-se bem" e na predominância de experiências agradáveis a partir de uma avaliação positiva da vida como um todo (PAVOT et al., 2008), atua sobre duas dimensões: afetiva ou emocional, composta por afetos positivos (prazer) e negativos (desprazer) e a cognitiva, relacionada com a satisfação com a vida (PAVOT et al., 1991).

Essa subjetividade refere-se a uma experiência consciente do indivíduo a partir do auto-relato de si, baseado em seus padrões, valores e crenças sobre uma vida feliz, apesar de avaliar o afeto e a satisfação como domínios específicos da vida (MELO, 2007). Portanto, o bem-estar pode ser descrito como um construto correspondente à satisfação do indivíduo com áreas diferentes da vida como: relações familiares, saúde, educação, personalidade, socialização, trabalho e conhecimento pessoal (ALBUQUERQUE et al., 2010).

Embora, elementos emocionais possam ser identificados tanto na eudaimónica quanto na hedónica este estudo enfoca a segunda vertente na dimensão cognitiva dos aspectos racionais ou intelectuais no intuito de levantar e caracterizar aspectos do ambiente de trabalho dos indivíduos por meio da definição do bem-estar subjetivo relacionados com a satisfação com a vida experienciada de forma global ou específica (ALBUQUERQUE et al., 2006). Ao englobar, em parte, o bem-estar subjetivo individual e os motivos que levam as pessoas a viverem de forma positiva as experiências da vida, suas aspirações passadas, comparações com outros, valores pessoais, entre outros (GALINHA et al., 2005).

Entre os componentes que constituem o BES, a satisfação com a vida pode ser considerada como um construto distinto que avalia cognitivamente e de forma global a qualidade da vida como um todo, ao assumir um julgamento valorativo desta (PAVOT et al., 2008). E, ao permitir que os sujeitos determinem seus próprios critérios de julgamento e os ponderem de acordo com suas escolhas, na medida em que tais atitudes em relação a sua própria vida afetem a forma como estes vivenciam seu estado de saúde (STRAUME et al., 2014).

Sentir-se bem ou malsucedido em domínios específicos da vida, tais como: engajamento, desempenho acadêmico, relacionamentos amorosos, relações familiares, entre outros, podem atuar como influenciadores em sua satisfação com a vida (PAVOT et al., 2008). Mesmo quando estes domínios não se limitam a experiências afetivas podem captar aspectos não afetivo da experiência que são importantes para os indivíduos, como por exemplo, o sucesso da pessoa em atingir metas de vida por ele valorizadas. Pois, embora esteja relacionada com o BES, esta pode ser considerada parcialmente independente dos aspectos afetivos (STRAUME et al., 2014).

A avaliação global de uma pessoa sobre sua satisfação com a vida pode atuar como um importante preditor no julgamento geral deste indivíduo sobre sua saúde, considerando que ambos estão intimamente ligados, uma vez que em alguns casos a saúde pode ter um efeito causal no bem-estar, pois a incidência de satisfação em uma área da vida tende a se estender a outros aspectos do bem-estar subjetivo e, sobre certas circunstancias o aumento da satisfação com a vida pode melhorar a saúde (STRAUME et al., 2014).

A saúde mental e o bem-estar descrevem nosso estado mental e como estamos nos sentindo ao lidar com a vida cotidiana, os quais impactam significativamente no bem-estar mental dos indivíduos (HARNOIS 
et al., 2002). Os problemas de saúde mental dos funcionários podem ser devido a fatores internos ou externos ao trabalho e, sem um gerenciamento eficaz, podem afetar seriamente a produtividade, as perspectivas de carreia e a saúde mental destes. Tendo em vista que, baixos níveis de bem-estar dos funcionários afetam negativamente a produtividade que por sua vez gera um impacto negativo significativo na saúde geral destes (DELOITTE, 2017).

Assim, para lidar com os problemas, pessoas felizes iniciam pensamentos e comportamentos que são adaptativos e úteis, enquanto, em média, as pessoas infelizes lidam de maneiras mais destrutivas. Por exemplo, as pessoas felizes são mais propensas a ver o lado positivo dos assuntos, orar, lutar diretamente com os problemas e procurar ajuda dos outros, enquanto as pessoas infelizes têm maior probabilidade de culpar os outros e a si mesmos (DIENER et al., 1997).

O efeito disso sobre a saúde mental pode ser tanto positivo, proporcionando contato social, senso de esforço coletivo e identidade social, quanto negativo como fonte de estresse psicológico relacionado às demandas de trabalho e falta de apoio social no local de trabalho (CERCARELLI et al., 2012). Pois, indivíduos afetados por problemas de saúde mental e insatisfação com suas atividades correm um risco substancialmente maior de se tornarem desligados da força de trabalho, sendo menos produtivos (LIM et al., 2000), experimentando níveis mais altos de problemas de saúde física e de se envolverem em acidentes (HARNOIS et al., 2002).

\section{METODOLOGIA}

Dado o fato de um dos objetivos desta pesquisa estar voltado para a identificação das percepções que os docentes têm sobre inveja, Bem-estar Subjetivo e saúde mental em seus locais de trabalho, optou-se por uma pesquisa cuja abordagem teórico-metodológica seja a de uma estudo qualitativa-descritivo. A escolha por este tipo de pesquisa se sustenta na possibilidade de se estabelecer, uma relação entre a realidade e os sujeitos de pesquisa (MINAYO et al., 2002). Contudo, a despeito da delimitação qualitativa desta pesquisa, não se abriu mão do auxílio de outros recursos metodológicas de cunho quantitativo que porventura vem a complementar este estudo. Por ter ciência da existência de outras abordagens que trataram dos mesmos temas aqui descrito, dentro de uma perspectiva quantitativa.

\section{Participantes}

O universo de pesquisa ou população deste estudo contou com a participação de 176 professores universitários. Destes, 101 (56,7\%) dos pesquisados são mulheres e os restantes 75 (42,1\%) são homens. Metade da amostra possui vínculo institucional como efetivos $(49,4 \%)$. O regime de trabalho predominante é T40 (94,9\%). A idade dos inquiridos é em média 32, 35 ( $D P=5,144)$ distribuída entre 24 e 51 anos, no entanto a maior concentração situa-se entre 30-38 anos (58,4\%). Em termos de distribuição por curso, 122 $(68,5 \%)$ são de administração e apenas (31,5\%) pertencente a outros cursos. Com relação ao tempo de atuação 54,5\% tem até 3 anos de docência e, por fim, (30,3\%) dos indivíduos em análise tem formação de mestre e apenas $(16,5)$ doutorado. Conforme pode-se observar na Tabela 1. 
Tabela 1: Dados sociodemográficos da amostra ( $n=176)$.

\begin{tabular}{|c|c|c|c|c|c|}
\hline \multicolumn{2}{|c|}{ Variáveis } & \multirow{2}{*}{$\begin{array}{l}\text { Frequência } \\
52\end{array}$} & \multirow{2}{*}{$\begin{array}{l}\text { Percentual } \\
29,2\end{array}$} & \multirow{2}{*}{$\begin{array}{l}\text { Percentual Válida } \\
29,2\end{array}$} & \multirow{2}{*}{$\begin{array}{l}\begin{array}{l}\text { Percentual } \\
\text { Acumulado }\end{array} \\
29,2 \\
\end{array}$} \\
\hline \multirow{3}{*}{ 1. Idade } & 24-29a. & & & & \\
\hline & 30-38a. & 104 & 58,4 & 58,4 & 87,6 \\
\hline & $>38 a$. & 22 & 12,4 & 12,4 & 100,0 \\
\hline \multirow{2}{*}{ 2. Sexo } & Masculino & 75 & 42,1 & 42,6 & 42,6 \\
\hline & Feminino & 101 & 56,7 & 57,4 & 100,0 \\
\hline \multirow{2}{*}{ 3. Vínculo } & Efetivo & 88 & 49,4 & 50,0 & 50,0 \\
\hline & Substituto & 88 & 49,4 & 50,0 & 100,0 \\
\hline \multirow{2}{*}{ 4. Regime de Trabalho } & T40 & 169 & 94,9 & 96,0 & 96,0 \\
\hline & T20 & 7 & 3,9 & 4,0 & 100,0 \\
\hline \multirow{2}{*}{ 5. Tempo de Docência } & Até 3 anos & 97 & 54,5 & 54,5 & 54,5 \\
\hline & Até 22 anos & 81 & 45,5 & 45,5 & 100,0 \\
\hline \multirow{2}{*}{ 6a. Formação } & Não Admin & 54 & 30,3 & 30,7 & 69,3 \\
\hline & Admin & 122 & 68,5 & 69,3 & 100,0 \\
\hline \multirow{10}{*}{ 6b. Curso } & Administração & 122 & 68,5 & 69,3 & 69,3 \\
\hline & Computação & 7 & 3,9 & 4,0 & 73,3 \\
\hline & Direito & 9 & 5,1 & 5,1 & 78,4 \\
\hline & Educação Física & 1 & 0,6 & 0,6 & 79,0 \\
\hline & Engenharia Civil & 3 & 1,7 & 1,7 & 80,7 \\
\hline & Física & 8 & 4,5 & 4,5 & 85,2 \\
\hline & Letras & 4 & 2,2 & 2,3 & 87,5 \\
\hline & Matemática & 10 & 5,6 & 5,7 & 93,2 \\
\hline & Pedagogia & 2 & 1,1 & 1,1 & 94,3 \\
\hline & Psicologia & 10 & 5,6 & 5,7 & 100,0 \\
\hline
\end{tabular}

\section{Instrumentos e Procedimentos}

Os participantes foram solicitados a preencherem um questionário com perguntas de caráter sociodemográfico para caracterizar a amostra (idade, sexo, vinculo, regime de trabalho, tempo de docência, instituição e curso) bem como, com três questões abertas que buscam captar a percepção dos docentes acerca dos construtos ao qual o instrumento se referia, a saber: (i) Se eu falar a palavra INVEJA o que passa na sua cabeça? Indique 3 palavras; (ii) Se eu falar a palavra BEM-ESTAR o que passa na sua cabeça? Indique 3 palavras; e, (iii) Se eu falar a palavra SAÚDE MENTAL o que passa na sua cabeça? Indique 3 palavras.

A pesquisa foi realizada por meio de survey online no qual era solicitado uma autorização para início da coleta de dados por meio do aceite do termo de consentimento livre e esclarecido (TCLE), de acordo com a resolução 510/16 do conselho Nacional de Saúde (CNS). Os dados coletados foram transcritos posteriormente em formato de texto eletrônico para serem processados pelo software Iramuteq (Interface de R pour les Analyses Multidimensionnelles de Textes et de Questionnaires), responsável por fazer a análise lexical das palavras presentes nos discursos dos sujeitos de pesquisa. A versão 7 foi utilizada, a opção pelo software se justifica por este ser desenvolvido em regime open source (código aberto) e distribuído livremente (software livre), o qual se encontra disponível no site responsável pela divulgação do software. ${ }^{1}$

Em relação aos procedimentos e as técnicas de análise, foram realizadas as seguintes etapas: Antes de realizar qualquer análise pelo iramuteq, é necessário preparar o texto a será analisado, inicialmente devese colocar os textos em um único arquivo do tipo bloco de notas que deve ser salvo em formato txt; Cada texto que será analisado, deverá conter uma linha de comando, expressa da seguinte forma: **** *palavras_chave_01; O texto deve ficar sem justificação, não usar letra do tipo itálico, negrito ou qualquer 
recurso fornecido pelo office; Para palavras compostas ou termos que fazem parte do mesmo contexto devese utilizar um traço do tipo underline entre estes. Esse recurso é entendido pelo software como um espaço em branco.

Para esta pesquisa as respostas referentes às perguntas foram agrupadas em três corpus e analisados por meio de Estatísticas textuais a qual permite inferir o número de ocorrências, frequência média das palavras, bem como formas e ainda a classificação gramatical reduzida desta. Foram utilizados os seguintes tratamentos analíticos para o texto: A análise de Especificidades que contrastar dados, sendo possível comparar banco de dados diferentes; análise de similitude (AFC) que permite inferir sobre a conexão existente entre os dados, a partir da formação de uma árvore de palavras, sob os quais é possível estabelecer nós centrais e, relacionar e criar conexões de acordo com sua raiz semântica; a Classificação Hierárquica Descendente ( $\mathrm{CHD}$ ), que rótula os segmentos de textos de acordo com as palavras lematizadas, formando grupos com base em sua frequência no texto, correlacionando por conteúdo, tema, semelhança e relação entre si; e, por meio criação de uma Nuvem de Palavras, a partir da qual é possível representar a frequência de palavras expressas no corpus, sendo que os termos com maior representatividade aprecem com a fonte em um tamanho maior e as menos representativas em tamanho menor.

\section{RESULTADOS E DISCUSSÃO}

Os dados textuais foram transcritos para um arquivo do bloco de notas do Windows e salvos na codificação UFT-8 para análise no software Iramuteq, o qual é hospedado no programa R (R core Team 2012), sendo divido em três arquivos separados, equivalente as três questões anteriormente apresentadas, dando origem a três corporas distintos. Após a revisão das respostas, aquelas que não correspondiam ao que fora perguntado foram eliminadas, de modo que os três corporas ficaram caraterizados da seguinte maneira (dispostos respectivamente na ordem das perguntas citadas acima). O Corpus 1_Inveja: integrou 519 ocorrências, das quais 137 foram aproveitadas (apareceram apenas uma vez em todo o corpus), ou seja, 65,55\% do total. O Corpus 2 Bem_Estar_Subjetivo: obteve 528 ocorrências, destas apenas 83 foram aproveitas (59,71\%), e, o Corpus 3_Saúde_Mental resultou em 517 ocorrências com aproveitamento de 135 palavras (62,50\%). Em seguida, foram reagrupadas em um único arquivo para dar início a análise conjunta de um único corpus, denominado de 'Percepção Docente'.

Quando esquematizado o corpus textual 'Percepção Docente' no Iramuteq, o software tratou os dados, no tempo de 1s, apresentando as seguintes inferências: 3 textos (número de resumos analisados); 75 Segmentos de Textos (ST); um total de 1564 ocorrências (total de palavras apresentadas no corpus); 493 formas (palavras sem contar repetição) e 298 hapax (que aparecem somente uma vez no texto) representando $60,45 \%$ das formas e $19,05 \%$ das ocorrências, com uma média de ocorrências por texto de 521, 33. Conforme pode ser observado no Figura 1. 


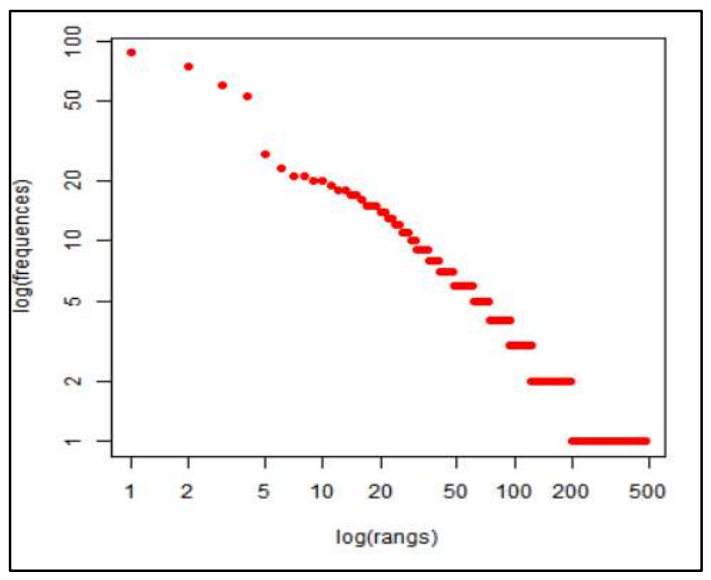

Figura 1: Apresentação dos resultados da análise estatística textual do Corpus 1_Inveja. Resumo: Número de textos: 3; Número de ocorrências: 1564; Número de formas: 493; Número de hápax: 298 (19, 05\% de ocorrências $-60,45 \%$ de formas).

O 'resumo' apresentado na Figura 1 traz a relação entre a frequência e a quantidade de formas do corpus que está em análise. A partir do gráfico acima, quanto maior é a frequência de uma forma/palavra, menor é a sua quantidade no texto. Sendo assim, as palavras com frequência 1 existem em grande quantidade no texto, e palavras com frequência 100 aparecem em menor quantidade (justificado por ser um padrão normal de corpus textuais menores).

Dando seguimento as análises os dados textuais foram submetidos a três tipos tratamento analítico: 1) Análise de Similitude; 2) Nuvens de Palavras; e 3) classificação Hierárquica Descendente (CHD). A CHD classifica os seguimentos de texto com base nos vocabulários para originar as classes de Unidade de contextos elementares (UCEs) por meio de uma análise de frequência e qui-quadrado $\left(\mathrm{X}^{2}\right)$, o qual expressa a força associativa entre as palavras e a sua respectiva classe quando o teste for maior que 3,84 , representando $p<0,0001$

As UCEs são consideradas as palavras que apresentam similaridade entre si e diferenciam-se dos demais seguimentos de texto (CAMARGO et al., 2013). A nuvem de palavras faz o agrupamento e a organização dos termos de acordo com a frequência que são citados (palavras mais em maior evidência são as mais frequentes). $\mathrm{E}$, a análise de similaridade verifica a conexidade entre as palavras, isto é, a ocorrência quando um termo é usado conjuntamente. Em todas a análise foram considerados adjetivos, advérbios, substantivos e verbos.

\section{Percepção Docente sobre a Inveja, Bem-Estar Subjetivo e Saúde Mental}

A inveja é reconhecida como um dos maiores problemas enraizados no seio da humanidade, ao ser considerada como o pior pecado entre os sete capitais por ser contra todas as virtudes e bondades (BARROWS, 2002). Uma vez que está não gera nenhum ganho, para o objeto de a admiração, sendo vista apenas como um prazer sádico, focada na satisfação prazerosa pelo mal de outro. Essa avaliação consciente da inveja como algo ruim, pecaminoso e triste que uma pessoa pode refletir sobre valores e objetivos pessoais e emocionais da vida do indivíduo. Em que reações afetivas tanto positivas quanto negativas podem refletir inconscientemente e influenciar estados físicos, sociais e mentais, em uma extensão maior que pode 
vir a interferir sobre sua própria satisfação de vida.

No entanto, deve haver um grau de convergência entre a satisfação com a vida e o bem-estar emocional, porque ambos dependem de avaliações positivas sobre domínios específicos da vida, como a qualidade dos relacionamentos sociais e conjugais, o sucesso nos ambientes de trabalho, os resultados da saúde física e a saúde mental (PAVOT et al., 2008). Embora possa haver alguma concordância sobre os componentes importantes da 'vida boa', como saúde e relacionamentos bem-sucedidos, os indivíduos provavelmente atribuirão pesos diferentes a esses componentes. Portanto, apesar de que a maioria dos sujeitos tenham relativamente pouco controle sobre os fatores do contexto de trabalho, no nível organizacional há um considerável campo inexplorado para abordar os fatores cruciais que afetam a saúde mental e o bem-estar em seu local de trabalho (LEE et al., 2014).

Para interpretar estes dados, foi feita uma 'Análise de Similitude' (Figura 3) deste corpus. A análise de similitude demostra as ligações existentes entre as formas de um corpus textual, permitindo inferir a construção e a estruturação de um texto incluindo entre estes os temas relativos ao corpus (SALVIATI, 2017). Por meio dessa análise é possível identificar a conexão existente entre as palavras, a partir de suas raízes semânticas lematizadas, bem como a identificação do conteúdo e da sua estrutura. Assim, foi possível compreender as ocorrências simultâneas entre as palavras e suas conexidades por meio de visão mais detalhes da estrutura do conteúdo do corpus referente a percepção dos docentes sobre a inveja, bem-estar subjetivo e saúde mental (Ver Figura 2).

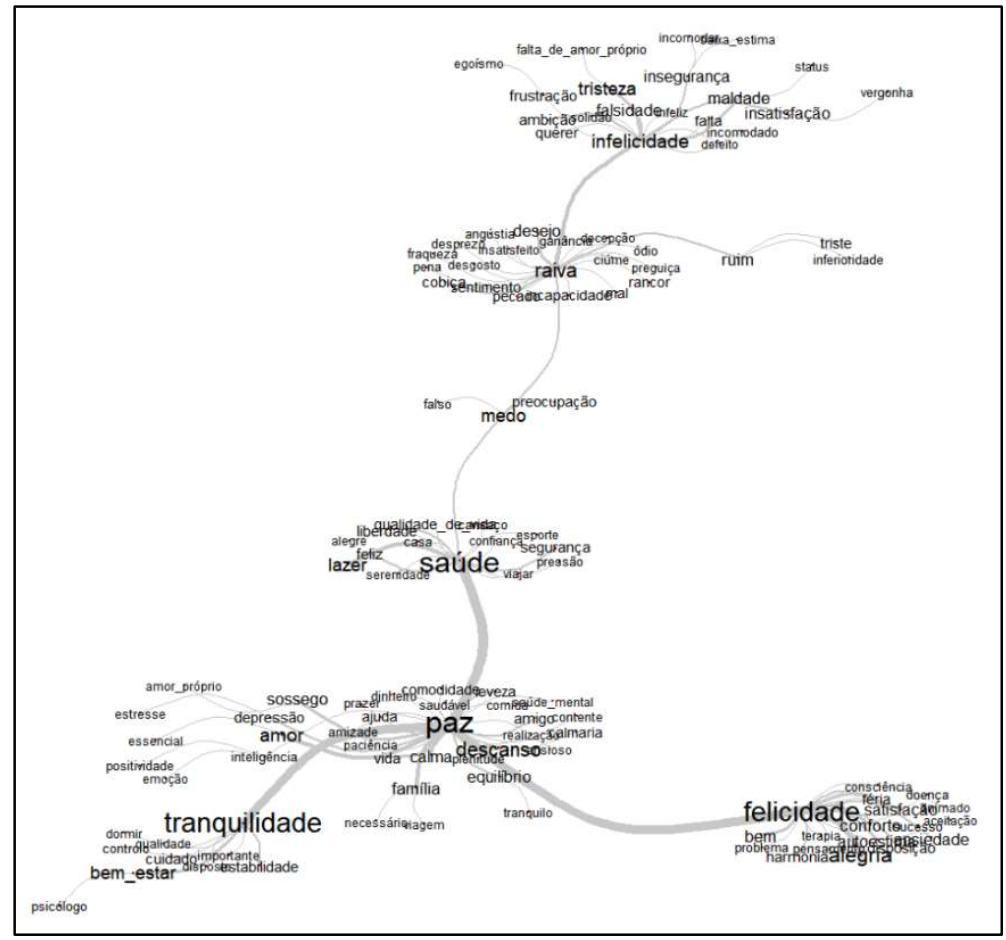

Figura 2: Análise de similitude dos construtos analisados.

Observa-se (Figura 2) que a palavra 'Paz' aparece em destaque (tendo 87 ocorrências) seguida das palavras 'Saúde' (74 ocorrências), 'Felicidade' (60 ocorrências), 'Tranquilidade' (53 ocorrências), 'Raiva' (27 ocorrências), 'Tristeza' (21 ocorrências) e, 'Infelicidade' (19 ocorrências). Embora as ocorrências entre elas sejam levemente distintas, verifica-se pela imagem que o vértice que liga as palavras 'Paz', 'Saúde', 
'Felicidade' e 'Tranquilidade', apresenta a mesma espessura, inferindo que as quatro estão muito próximas nos textos, da mesma forma que se verifica uma aproximação moderada entre as palavras 'Raiva', 'Infelicidade' e 'Tristeza'. Da ramificação da palavra 'Paz', emergem expressões como 'descanso', 'calma', 'plenitude', 'sossego' e etc., que por meio da representação na imagem, bem como pela leitura feita anteriormente, permite inferir que por se tratar de questões relacionadas com a percepção de saúde, bemestar e convívio social e compreensível a presença forte desta palavra nessa relação.

A palavra 'Felicidade' tem uma ramificação muito diversa. Pela análise de similitude feita pelo Iramuteq, isto significa que, mesmo as demais expressões estando diretamente ligadas ao eixo central (Paz), elas possuem pouca relação direta entre si. Num extremo vemos a expressão 'problema', 'doença' e 'ansiedade', entre outros. Como 'Felicidade' está diretamente ligado a 'Paz', 'Tranquilidade' e 'Saúde', é possível inferir que a felicidade apresentou certa associação na concepção dos sujeitos com esses termos, indicando que este estado tem uma relação significativa com os outros três.

Para Veenhoven (2012), a palavra 'felicidade' é usada de várias maneiras. No sentido mais amplo, é um termo abrangente para tudo o que é bom, sendo frequentemente associada a termos como bem-estar ou qualidade de vida, denotando tanto o bem-estar individual quanto social. Diz respeito à satisfação geral e à vida como um todo a partir do grau em que um indivíduo julga favoravelmente a qualidade geral de sua própria vida. Segundo Valério (2012), a felicidade, tal como a alegria e o otimismo começa a ser um domínio de investigação do bem-estar subjetivo emerso da psicologia positiva.

A partir das ramificações apresentadas no eixo 'Saúde', observa-se expressões como 'liberdade', 'Feliz', 'Alegre' e 'Pressão' que derivam diretamente da sub-ramificação anteriores, inferindo que a saúde pode depender de estado de alegria e felicidade, bem como está associada a pressões. Dessa ramificação é possível ver um sub-ramificação moderada com expressões como 'medo', 'preocupação' e, 'falso' ligados diretamente da sub-ramificação 'raiva', propondo as ramificações que compõem esse eixo tem certa associação com o estado de saúde. No ramo direito, é visível termos como angústia, 'rancor' 'desgosto' 'decepção', 'ódio' entre outros se ramificando diretamente da sub-ramificação 'Raiva'. Por meio dessa representação, é possível vislumbrar à força destruidora que ataca as próprias pessoas ou qualidades que o indivíduo admira.

Por fim, pode-se observar que as expressões 'Raiva' e 'Infelicidade' possuem uma forte ligação possibilitando a inferência de que ambas podem indicar o sentimento de raiva pode estar relacionado a uma dor trazida pela consciente de suas próprias deficiências, ocasionado infelicidade ou pela existência atributos admiráveis em outro indivíduo que não possuem. Essa ligação traz uma percepção de um tipo de inveja com qualidade perniciosa que inspirar afetos negativos. De acordo com Ghadi (2018) emoções negativas podem ocasionar a perdas e eventos organizacionais que impedem a realização de metas.

A Figura 4, conhecida como nuvem de palavras, representa de forma gráfica a organização e o agrupamento das expressões presentes no corpus. Trata-se de uma análise lexical simples, cuja estrutura da figura é formada em função da quantidade numérica de ocorrências que cada palavra tem no resultado da análise efetuada pelo software. Quanto maior e mais centralizada estiver uma palavra na nuvem, maior é o 
grau de sua evocação pelos sujeitos. Ao passo que quanto mais afastada e menor seu tamanho, menor é o seu grau de evocação (CAMARGO et al., 2013b). Percebe-se que para o Corpus em análise se destacam expressões como: Paz, saúde, felicidade tranquilidade, raiva, maldade, tristeza, infelicidade, descanso, familia, alegria, bem-estar, entre outros.

Esses termos em destaque demostram que na percepção dos docentes permite inferir que esses sentimentos em parte estão presentes expressos por meio emoções desagradáveis que por vezes desencadeiam hostilidade, agressividade, sentimentos de inferioridade e outros comportamentos violentos em relação às relações interpessoais (GHADI, 2018). E, por outro lado evidenciam que estados de saúde mental e bem-estar são necessários, especialmente no cenário acadêmico, onde os sujeitos são incentivados a buscar uma vantagem competitiva, e por vezes são recompensados e melhor vistos pelo desempenho que apresentam aos pares.

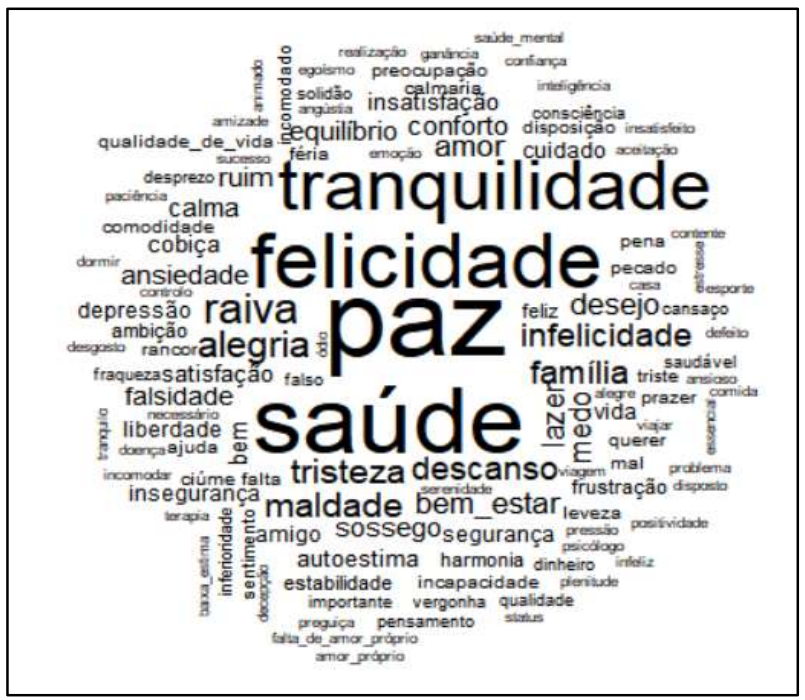

Figura 3: Nuvem de palavras.

Para Klein (1991) uma das qualidades mais invejadas é a paz de espírito, componente com maior destaque dado pelos docentes. Embora, muitas vezes a inveja prejudicar os bons sentimentos sem que a pessoa invejosa tenha consciência disso, o que pode tornar a inveja tão difícil de administrar e tão subtilmente perniciosa. Sendo Cohen-Charash (2009) inveja pode ser conceituada como uma emoção desagradável que está relacionado negativamente a expressões como ansiedade, ódio, depressão, inferioridade, autocrítica e o desejo de prejudicar outros.

Com relação a análise de classificação Hierárquica descendente (CHD) realizada a partir da construção de um esquema hierárquico de classes dos vocabulários no corpus foi possível propor o conteúdo de cada classe gerada pelo software permitindo uma compreensão dos grupos e ideias centrais identificadas do corpus (SALVIATI, 2017). Em um tempo de 13s, o corpus utilizado na CHD, foi classificado em 75 Segmentos de Texto, 1564 ocorrências, 473 formas ativas, além da CHD apresentar dados novos, como a quantidade de lemas (um total de 479), a quantidade de Segmentos de Texto classificados (84\% de um total de 75 ST), isto é, os ST que foram aproveitados para a CHD, e que seguiram em análise.

Para a análise de CHD, é necessário ter um aproveitamento de no mínimo 70\% de ST pelo Iramuteq, tendo em vista que se a retenção for menor que está, o corpus tonar-se pouco representativo para este tipo 
de análise, ou que existe uma diversificação muito diversificada do corpus dificultado sua hierarquização. As classes constituídas pelo CHD a partir do corpus em análise geraram 6 classes conforme pode ser observado na Figura 4.

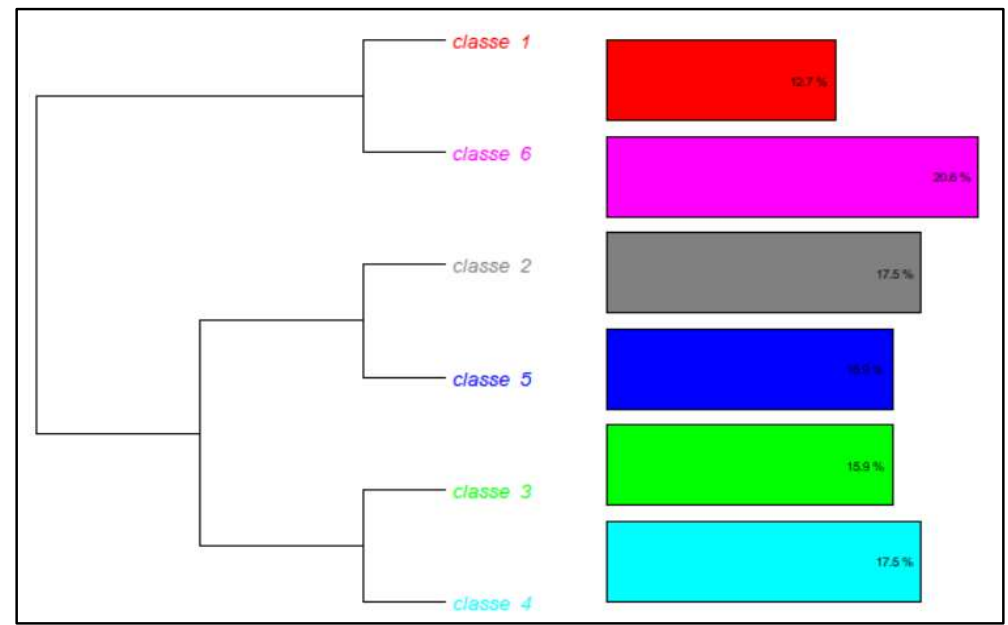

Figura 4: Dendograma da classificação hierárquica descendente dos construtos.

Neste dendograma, observa-se que teve como resultado a criação de dois subcorpora, originando as Classes 1 e 6, tendo cada uma delas 8 ST, representando 12,7\% e 13 ST (20,63\%) respectivamente do corpus total classificado. Desses subcorpora, originou-se mais quatro classes; as Classes 2 (11 ST representando 17,46\% do corpus total) e 5 (10 ST representando 15,87\%), e a Classe 3 (10 ST representando 15,87\% do corpus total) e a Classe 4 (11 ST representando 17,46 \% do corpus total).

A partir dos dados oriundos do corpus textual apresentados na Figura $\mathrm{X}$, é possível observar os resumos constituintes de cada classe, desde a de menor ocorrência e agregação (Classe 5 e 3, com 10 ST respectivamente), até a de maior ocorrência, mais agregada (Classe 6, com 13 ST). Esta inferência de Classes agregada e menos agregadas, refere-se à quantidade de ST que a Classe possui, em relação ao corpus total. Quando mais ST uma classe possuir, mais agregada é, isto é, os vocabulários de uma ST correlacionam-se com os presentes em outros ST, que pode ser, inclusive, de variáveis diferente. Da mesma forma, quanto menor for o número de ST que integram a Classe, menos agregada pode ser considerada, ou seja, os vocabulários que a compõem pouco se relacionam com os de outro ST e de outras Classes (ALCIONE, 2018).

\section{CONCLUSÕES}

O estudo adotou uma abordagem qualitativa, de natureza exploratória, dando total liberdade de pensamento aos participantes. Optou-se por analisar a percepção docente sobre as principais expressões que estes associam ao invocar os termos: inveja, bem-estar subjetivo e saúde mental em seus locais de trabalho. O resultado dessas expressões, trazem a visão de um ambiente em que possivelmente a intensificação do trabalho docente impacta diretamente sobre a qualidade da vida acadêmica, pois deixa transparecer a necessidade de descanso, tranquilidade, paz, saúde, entre outros.

É possível observar que a intensidade de energia colocada na efetividade do trabalho requer do docente um dispêndio muito grande de energia física, intelectual e emocional em termos de resultados evidentemente expressas nas palavras informados pelos docentes na pesquisa. A influência do ambiente 
social, incluindo família, amigos e colegas de trabalho tem implicações sobre o entendimento acerca do que pode ser considerado como qualidade de vida para um indivíduo, para alguns alcançar um papel social de destaque, abdicar de alguns eventos/acontecimentos, a fim de se preparar para uma carreira de sucesso, desejar alcançar um comportamento socialmente aceito, entre outros fatores podem ser associados a ideia de qualidade de vida.

As expressões evidenciam uma aspiração do que pode se considerar como uma experiência positiva atrelada a essa ideia de qualidade de vida, ao invocar termos como: conforto, trabalho, família, tranquilidade, entre outros, incluindo um estado emocional e fatores relacionados a saúde. Diante disso, espera-se que este estudo possa contribuir para uma melhor compreensão das expressões que envolvem a inveja, bem-estar subjetivo e a saúde mental na perspectiva de professores universitários de instituições públicas em seus locais de trabalho, de modo a fornecer subsídios para mobilizar práticas voltadas a melhorar as relações sociais nesse ambiente, e que favoreçam uma melhora na qualidade de vida deste público, possibilitando, assim, um local de trabalho menos estressante, competitivo e angustiante.

Nesse sentido, evidencia-se a necessidade de pesquisas que venham a aprofundar as dimensões subjetivas desses construtos no universo acadêmico, especialmente no contexto dos professores universitários, mobilizando reflexões que conduzam a concretização de ações que venham a reduzir a inveja e beneficiar o bem-estar e a saúde mental destes indivíduos em seus locais de trabalho.

A principal limitação, no entanto, talvez seja a especificidade da amostra utilizada, a qual se constitui unicamente de professores universitários, este grupo se caracteriza como uma amostra de baixa variabilidade, uma vez que é composta por indivíduos com padrões e dinâmicas de vida muito semelhantes entre si, o que pode ter exercido certa influência na configuração das respostas. Além de não ser uma amostra representativo de toda a população docente de instituições de ensino superior público. Assim, estudos futuros podem ser pensados objetivando superar tais limitações expostas, ao incluir a realização de uma pesquisa transversal e uma amostra mais diversificada de diferentes instituições do país, por exemplo corroborando e/ou ampliando os principais resultados aqui encontrados.

Por fim, as condições e situações pessoais de um indivíduo no campo social criam um ambiente propício para o desenvolvimento da inveja, impactando no desempenho dos funcionários, absenteísmos, nas taxas de doenças, na rotatividade de pessoal e diretamente na deterioração do bem-estar mental no trabalho.

\section{REFERÊNCIAS}

ALBUQUERQUE, F. J. B.; SOUSA, F. M.; MARTINS, C. R.. Validação das escalas de satisfação com a vida e afetos para idosos rurais. Psico, v.41, n.1, p.85-92, 2010.

ALBUQUERQUE, F. J. B.; NORIEGA, J. A. V.; COELHO, J. A. P. M.; NEVES, M. T. S.; MARTINS, C. R.. Valores humanos básicos como preditores do bem-estar subjetivo. Psico, v.37, n.2, p.131-137, 2006.

ALBUQUERQUE, A. S.; TRÓCCOLI, B. T.. Desenvolvimento de uma escala de bem-estar subjetivo [Development of a subjective well-being scale]. Psicologia: teoria e pesquisa, v.20, n.1, p.53-64, 2004.

CERCARELLI, R.; ALLSOP, S.; EVANS, M.; VELANDER, F.. Reducing Alcohol-Related Harm in the Workplace: An Evidence Review: Full Report, Victorian Health Promotion Foundation, Melbourne. 2012.

COHEN-CHARASH, Y.. Episodic envy. Journal of Applied Social Psychology, v.39, p.2128-2173, 2009. 
CRUSIUS, J.; LANGE, J.. How do people respond to threatened social status? Moderators of benign versus malicious envy. In: SMITH, R. H.; MERLONE, U.; DUFFY, M. K. I Envy at Work and in Organizations: Research, Theory, and Applications. NewYork: Oxford University Press, 2017. p.85110.

DIENER, E.; PRESSMAN, S. D.; HUNTER, J.; DELGADILLOCHASE, D.. If, Why, and When Subjective Well-Being Influences Health, and Future Needed Research. Applied Psychology: Health and Well-Being, v.9, n.2, p.133-167 2017. DOI: http://doi:10.1111/aphw.12090

FISKE, S. T.. Envy up, scorn down: How comparison divides us. American Psychologist, v.65, p.698-706, 2010.

GALINHA, I.; RIBEIRO, J. L. P.. História e evolução do conceito de bem-estar subjectivo. Psicologia, Saúde \& Doenças, v.6, n.2, p.203-214, 2005.

GHADI, M. Y.. Empirical examination of theoretical model of workplace envy: evidences from Jordan. Management Research Review, v.41, n.12, p.1438-1459, 2018. DOI: http://doi.org/10.1108/MRR-06-2017-0185

HENNIGER, N. E.; HARRIS, C. R.. Envy across adulthood: the what and the who. Basic and Applied Social Psychology, v.37, p.303-318, 2015

KIM, S.; O'NEILL, J. W.; CHO, H.. When does an employee not help coworkers? The effect of leader-member exchange on employee envy and organizational citizenship behavior. International Journal of Hospitality Management, v.29, n.3, p.530-537, 2010

KLEIN, M.. Inveja e gradtidão e outros trabalhos 1946-1963. 4 ed. Rio de janeiro: Imago, 1991.

LEE, N. K.; ROCHE, A.; DURAISINGAM, V.; FISCHER, J. A.; CAMERON, J.. Effective interventions for mental health in male-dominated workplaces. Mental Health Review Journal, v.19, n.4, p.237-250, 2014. DOI: http://doi.org/10.1108/MHRJ-09-2014-0034

MELO, S. C. A.. Bem-estar subjetivo e bem-estar no trabalho: um estudo com idosos que trabalham. Dissertação (Mestrado) - Universidade Federal de Uberlândia, Uberlândia, 2007.

PARROTT, W. G.; SMITH, R. H.. Distinguishing the experiences of envy and jealousy. Journal of Personality and Sociai Psychology, v.64, p.906-920, 1993.
PAVOT, W.; DIENER, E.. Review of the satisfaction with life scale. In. DIENER, E.. Assessing Well-Being: The Collected Works of Ed Diener. Social Indicators Research, series 39, Springer Science Business Media. 2009. p.101-117. DOI: http://doi.org/10.1007/978-90-481-2354-45

PAVOT, W.; DIENER, E.. The Satisfaction With Life Scale and the emerging construct of life satisfaction. The Journal of Positive Psychology, v.3, n.2, p.137-152, 2008.

PAVOT, W.; DIENER, E.; COLVIN, R.; SANDVIK, E.. Further Validation of the Satisfaction with Life Scale: Evidence for the Cross-Method Convergence of Well-Being Measures. Journal of Personality Assessment, v.57, n.1, p.149-161, 1991.

SHIN, D. C.; JOHNSON, D. M.. Avowed happiness as an overall assessment of the quality of life. Social Indicators Research, v.5, p.475-492, 1978.

SMITH, R. H.; KIM, S. H.. Comprehending Envy. Psychological Bulletin, v.133, n.1, p.46-64, 2007.

STERLING, C.; VEN, N. V.; SMITH, R. H.. The two faces of envy: Studying benign and malicious envy in the workplace. In: SMITH, R. H.; MERLONE, U.; DUFFY, M. K.. Envy at Work and in Organizations: Research, Theory, and Applications. Oxford: Oxford University Press, 2016. p.57-84. DOI: http://doi.org/10.1093/acprof:oso/9780190228057.003.000 $\underline{3}$

STRAUME, L. V.; VITTERSO, J.. Well-Being at Work: Some Differences Between Life Satisfaction and Personal Growth as Predictors of Subjective Health and Sick-Leave. J Happiness Stud., v.16, n.1, p.149-168, 2014.

TIBERIUS, V.; HALL, A.. Normative theory and psychological research: Hedonism, eudaimonism, and why it matters. Journal of Positive Psychology, v.5, p.212-225, 2010.

VEN, N. V.; ZEELENBERG, M.; PIETERS, R.. Leveling up and down: the experiences of benign and malicious envy. Emotion, v.9, n.3, p.419-429, 2009.

VEENHOVEN, R... Happiness, also known as life satisfaction and subjective well-being..In: KENNETH, C. L.; ALEX, C. M.; SIRGY, M. J.. Handbook of Social Indicators and Quality of Life Research. Dordrecht: Springer Publishers, 2012. p.63-77. DOI: http://doi.org/10.1007/978-94-007-2421-1 3

VIDAILLET, B.. Workplace envy. Palgrave Macmillan, 2008.

WOYCIEKOSKI, C.; STENERT, F.; HUTZ, C. S.. Determinantes do Bem-Estar Subjetivo. Psico, v.43, n.3, p.280-288, 2012.

A CBPC - Companhia Brasileira de Produção Científica (CNPJ: 11.221.422/0001-03) detém os direitos materiais desta publicação. Os direitos referem-se à publicação do trabalho em qualquer parte do mundo, incluindo os direitos às renovações, expansões e disseminações da contribuição, bem como outros direitos subsidiários. Todos os trabalhos publicados eletronicamente poderão posteriormente ser publicados em coletâneas impressas sob coordenação da Sustenere Publishing, da Companhia Brasileira de Produção Científica e seus parceiros autorizados. Os (as) autores (as) preservam os direitos autorais, mas não têm permissão para a publicação da contribuição em outro meio, impresso ou digital, em português ou em tradução. 